\begin{tabular}{|c|c|c|}
\hline Raizes, & - 0 - & Eric Sabourin \\
\hline AnoXVIII, & & Pesquisador do Centro de Cooperação Internacional em Pesquisa Agronômica para o \\
\hline$N^{\circ} 20$ & & Desenvolvimento Rural, professor visitante na Universidade Federal da Paraíba, \\
\hline novembro/ & • & CampinaGrande -E-mail:eric.sabourin@cirad.fr \\
\hline 99 & & \\
\hline pp. 132-143 & 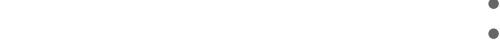 & \\
\hline
\end{tabular}

\title{
Meio ambiente e sustentabilidade da agricultura familiar no semi-árido Nordestino
}

\begin{abstract}
RESUMO
$\mathrm{O}$ artigo trata da relação entre meio-ambiente e sustentabilidade da agricultura familiar no semi-árido brasileiro no contexto da globalização a partir do acompanhamento de diversos projetos de desenvolvimento rural local. O texto aponta para a necessidade de completar o enfoque da viabilidade econômica e da viabilidade ecológica pela consideração de uma viabilidade social, fundada na diversidade das formas de organização local e num ambiente institucional mais favorável. Discute-se em seguida a questão das políticas locais de desenvolvimento sustentável, em particular quanto à gestão do meio ambiente, ao manejo e à recuperação dos agro-ecossistemas que constituem a base da agricultura familiar nordestina. Algumas pistas e alternativas são identificadas em termos de organização dos atores locais, produção e divulgação de referências técnicas para manejo dos agro-ecossistemas locais.

Palavras-chave: agricultura familiar, sustentabilidade, viabilidade sócio-econômica, agro-ecossistemas,
\end{abstract}

\section{ABSTRACT}

The first section of this paper introduces the discussion about environment, sustainable development and family agriculture in the globalisation context. It shows the necessity to complete economical and ecological viability approach by the consideration of a social viability, based on the diversity of local organisation forms and on a more favourable institutional environment. The second section discusses the question of sustainable development local policies, particularly environment management and agro-ecosystem's rehabilitation, which are the basis of the Northeast family agriculture. The author analyses the main obstacles to local application of sustainable development speeches and recommendations. Several issues and alternatives are identified on the matter of local organisation or around the elaboration and the dissemination of technical references more adapted to the diversity of social reality and ecosystem's management.

Key words: family agriculture, sustainability, semiarid area.

\section{Introdução}

Hoje nenhum ecologista, mesmo radical, negaria que a sobrevivência da crescente população humana passa pela intensificação do uso agropecuário dos ecossistemas cultivados. Por outra parte, ficou comprovado que a generalização do modelo de agricul- tura motorizada, mecanizada, consumidora de adubos minerais e agrotóxicos custosos, desenvolvido a partir de meados do Século XX, nos países industrializados não era mais sustentável nem aceitável (Mazoyer e Roudart, 1997). De fato, as formas de agricultura baseadas"na mão de obra familiar e usando poucos insumos externos são majoritárias no mundo (Reijntjes et al., 1992). Elas continuam ocupando e alimentando grande parte da população ativa dos países em desenvolvimento. Algumas dessas agriculturas familiares, mostram uma extraordinária capacidade de invenção e de adaptação específica ao longo dos anos (Engel, 1997). Esta é uma das realidades globalizadas do nosso planeta. Infelizmente, para os tomadores de decisão na escala do desenvolvimento local - por exemplo os prefeitos municipais eleitos para quatro anos - a sustentabilidade a longo prazo da agricultura familiar não constitui ainda um argumento forte. Eles querem apenas saber se vale a pena investir no apoio à agricultura familiar e de que maneira, para garantir resultados. Portanto, uma das principais questões colocadas pcra os trabalhos de pesquisa e desenvolvimenvo visando o fortalecimento da agricultura faoiliar tem a ver, não somente com a sustentabinidade desses sistemas de produção, mas também com a sua viabilidade a curto prazo, num contexto de integração global dos intercâmbios e de degradação localizada dos ecossistemas. Não se pretende analisar aqui a evolução da política pública brasileira em 
matéria de agricultura familiar, mas ao contrário, esclarecer os termos do debate sobre a sua sustentabilidade na escala local ou microrregional, apontando para algumas alternativas de articulação entre ação coletiva, políticas locais e política nacional.

A primeira parte introduz o tema da viabilidade social da agricultura familiar como base essencial da sua sustentabilidade ${ }^{1}$. De fato, as transformações técnicas da agricultura familiar permanecem estreitamente ligadas às mudanças sociais, institucionais ou à evolução do “ambiente institucional” (Abramovay, 1998). Na segunda parte, são abordados alguns dos desafios colocados pela questão da aplicação de políticas locais de desenvolvimento sustentável, no contexto da globalização, a partir de exemplos no Nordeste semi-árido.

\section{Sustentabilidade e viabilidade da agricultura familiar}

\subsection{Da reprodutibilidade agro- ecológica para a sustentabilidade política}

A noção de sustentabilidade foi logo aproximada àquela de agricultura familiar (Chambers e Conway, 1992; Ehlers, 1996; Veiga, 1994). Mas, em que o conceito de sustentabilidade contribui hoje para definir melhor a viabilidade econômica, ecológica e social da agricultura familiar?
Atrás do termo "agricultura sustentável" encontra-se o conceito de desenvolvimento sustentável (Carvalho, 1995; Magalhães, 1995). Segundo as Nações Unidas, "éo desenvolvimento que satisfaz as necessidades da geração presente sem comprometer as possibilidades das futuras gerações em satisfazer as suas necessidades" (CMMAD, 1991). Para Kitamura (1994), a noção de desenvolvimento sustentável é fundada num princípio de base: "o estoque de recursos naturais deve ser mantido constante ou renovado". Mas, segundo ele, esta noção esconde duas idéias chave. Primeiro, falar de "necessidades", além da amplitude do termo, faz referência, implicitamente, às camadas mais pobres da sociedade para as quais muitas dessas "necessidades" - mesmo básicas - não estão sendo satisfeitas. É, entre outras categorias, o caso dos segmentos mais pobres ou marginalizados da agricultura familiar. Segundo, existem limites impostos pela tecnologia, pela demografia e pela organização social sobre a capacidade e habilidade do meio ambiente em prover as necessidades da geração presente e das futuras. Finalmente, existem limites institucionais que são talvez mais graves que as limitações ecológicas e tecnológicas. Em outras palavras, mudar os sistemas técnicos exige aprendizagem individual e coletiva dos atores locais, além da disponibilidade da inovação, da informação ou da formação, o que supõe transformações sociais ou institucionais.

Quanto a sustentabilidade ecológica, os efeitos depredadores da agricultura em áreas recém colonizadas (Cerrados, Meio Norte e Amazônia) ou sujeitas à riscos de degradação (semi-árido nordestino) não representam ainda um problema fundamental para a agricultura empresarial, enquanto permanecer certa disponibilidade de terras nessas regiões. Efeitos de degradação do meio ambiente apenas vêm a ser publicamente questionados quando existem conflitos de interesse ou de acesso à esses recursos, por exemplo entre a agricultura patronal, os produtores familiares e os sem terra, ou as comunidades indígenas.

A mídia deu recentemente um exemplo desta realidade, procurando os culpáveis dos fogos no Estado de Roraima e indicando, em particular, a responsabilidade da agricultura de roça e queima de pequenos produtores precários. Leroy (1998) lembra o debate entre os "ambientalistas que acusam (..) setores dos sem-terra de ocupar áreas de floresta ou de mata e de promoverem a devastação (..) e o MST, querendo enfrentar essa situação, produzindo e preservando o meio ambiente". Ele agrega "o debate sobre preservação é insuficiente.. (..) pois, para a sustentabilidade do país, (..) a maior contribuição dos assentamentos de reforma agrária, é justamente criarnovas dinâmicas de desenvolvimento".

- ${ }^{1}$ A noção bastante complexa de sustentabilidade, embora diversamente interpretada, é onipresente - nos discursos de hoje. O conceito, aparentemente, tem tudo para conseguir a unanimidade. Bil-

- leaud (1995) lembra como, inclusive nos países desenvolvidos, ele é pouco discutido ou controverti-

- do, mas, mesmo assim, continua incerto, para não dizer pouco seguro. 
Quanto à situação dos “pobres”, o Banco Mundial (1990) defende a tese da luta contra a pobreza rural na América Latina, associada ao fortalecimento da agricultura familiar como base estratégica de desenvolvimento rural sustentável. A defesa da agricultura familiar não se deve somente à sua capacidade social de absorver mão-de-obra no campo, mas de gerar crescimento econômico (Banco Mundial, Brasil, 1993). Este argumento, foi retomado em discursos recentes ${ }^{2}$, mas interpretado de diversas maneiras no Brasil. O fato de existir um amplo setor da agricultura familiar cada vez mais integrado ao mercado e mais organizado não constitui ainda uma força política suficiente para garantir a aplicação efetiva de políticas públicas específicas. Isto levanta a questão das limitações da proposta de desenvolvimento sustentável no contexto econômico atual. Kitamura (1994) lembra que a economia é diferente da ética. Em realidade, faltam diálogo e alianças entre os segmentos dos produtores, do mercado, da agroindústria, e por suposto, do Estado. A repartição da informação e do poder político e financeiro é ainda demasiada assimétrica para garantir negociações que permitam uma co-gestão da política agrícola.

De fato, no Brasil, a agricultura familiar não representa ainda uma real prioridade para as políti- cas públicas agrícolas comparada com a agricultura empresarial que gera divisas, ou, com o latifúndio que gera sustentação política por parte das oligarquias rurais e dos grupos políticos tradicionais. De certa maneira, a agricultura familiar pode tornar-se vítima das suas qualidades ou do seu sucesso, sendo mais adaptada às mutações climáticas e econômicas pelas suas estratégias de limitação dos riscos e de "auto-exploração" da mão de obra familiar (Chayanov, 1966). Ela aparece até como eficiente, competitiva e flexível, comparada com a grande empresa agropecuária (Vieira, 1995). Delgado (1995), escreve "ela se adapta a reconversões sucessivas e rápidas, responde às mudanças dos mercado e aos impulsos das políticas públicas". É inegável que a agricultura familiar resista e se adapta. Mas a quê custo, com que tipo de remuneração do capital, da força de trabalho, e gerando que renda? Esta é a outra cara da moeda quanto à viabilidade econômica e social da agricultura familiar.

\subsection{A viabilidade social e econômica da agricultura}

A viabilidade econômica e social da agricultura familiar é, de maneira geral, associada à reprodução dessas unidades familiares de produção. A especificidade da lógica sócio-econômica da agricultura familiar foi evidenciada por vários autores (Chayanov, 1966; Abramovay, 1992; Lamarche, 1993). A viabilidade econômica da agricultura familiar foi definida em termos de manutenção, conservação e reprodução dos fatores de produção. Com a redução dos preços agrícolas (em particular dos cereais) desde os anos 70 , os sistemas familiares de produção de grãos (feijão e milho) são economicamente insustentáveis nos preços do mercado (Mazoyer e Roudart, 1997). Certas unidades familiares, de tipo camponês, conseguem se manter através do autoconsumo e do mercado local, como foi demostrado no Nordeste (Oliveira et al., 1997). Se as outras não desapareceram ainda é precisamente porque a viabilidade econômica e técnica da agricultura familiar não pode ser visualizada somente sob o aspecto do mercado. Ganha ao ser analisada também do ponto de vista social, quer dizer a partir da organização social das estruturas produtivas e do manejo dos fatores técnicos (Sabourin, 1999). Isto tem a ver com a evolução das práticas de acesso, distribuição, transmissão e gestão dos fatores de produção (ver box 1).

A noção de viabilidade social, ou de vivabilité (Landais, 1998) além do aspecto restrito da reprodução do patrimônio e da força de trabalho, obriga a considerar ou-

- 2 Ver o argumento que Joseph Stiglitz (1998a e b), Vice Presidente e Economista Chefe do Banco - Mundial repetiu em parte em Brasília em julho passado, defendendo o papel multiplicador da re-

- forma agrária em termos de crescimento econômico e enfatizando os erros das políticas econômi-

- cas neo-liberais. Segundo ele, "a liberalização dos mercados e o combate à inflação não são suficien-

- tes para garantir uma alocação mais demócrática, justa e sustentável de recursos". Chama para "a

- necessidade da intervenção dos Estados na regulação dos mercados, nos investimentos públicos e nas

- políticas de transferência de tecnologia" (tradução nossa). 
Box 3:

Sustentabilidade e viabilidade sócio-econômica da Agricultura familiar

As mudanças nos processos de produção, nos processos de valorização e comercialização dos produtos, de manejo dos recursos naturais e nas outras atividades das famílias rurais podem ser estudadas e logo avaliadas em função da sustentabilidade das unidades de produção familiar.

0 Grupo de Pesquisa sobre Produção Familiar da UFPB oferece uma definição para a viabilidade econômica e social da agricultura familiar.

"Considera-se a viabilidade da produção familiar no seu sentido amplo que abrange os aspectos econômicos, sociais, ambientais e culturais. Para uma dada região ou localidade, ela corresponde assim, à reprodução 'ampla' das diversas unidades de produção (família, terras e patrimônio) de uma localidade ou região determinada, garantindo a integração econômica, social e cultural das novas gerações e a manutenção dos agro-ecossistemas".

Para completar esta definição, teria que precisar os critérios ou indicadores que correspondem, para cada situação dada, aos tais patamares de sustentabilidade. Essa definição determina pelo menos quatro principais vertentes: a viabilidade econômica, a viabilidade social, a transmissibilidade do patrimônio e a reprodutibilidade ambiental ou agro-ecológica dos ecossistemas cultivados.

Esses componentes foram definidos por Landais (1998):

- a viabilidade econômica: é ligada à constituição da renda da família, formada a partir do conjunto das atividades, incluindo as transferências e os encargos públicos. A estabilizaccão dos sistemas de produção depende dos seus resultados técnico-econômicos, mas também, da sua autonomia, da sua capacidade de resistência às variações do clima (resiliência) e da natureza das relações contratuais com os clientes e fornecedores;

- a viabilidade social: depende da capacidade do agricultor a dominar o funcionamento do sistema, a assumir riscos; mas, também, da capacidade de apoio da rede social, na qual ele está integrado. Isto tem a ver com a sua integração no tecido social agropecuário ou rural e, com a densidade e a qualidade deste ambiente social;

- a transmissibilidade: tem a ver com os ativos materiais, mas também incorporais, ou também com o "status" dessas atividades na sociedade local;

- a reprodutibilidade agro-ecológica: a preservação dos recursos naturais (água em quantidade e qualidade, fertilidade dos solos) constitui um critério de base no manejo dos sistemas de produção que passam, às vezes, por importantes problemas de degradação (erosão nas encostas...).

tras escalas que aquela da unidade de produção familiar. Uma tem a ver com o espaço local e outra com o ambiente institucional externo. Quem fala de agricultura familiar, faz referência a uma coletividade local. Mendras (1978) lembra que a noção de agricultura camponesa (diferente daquela de agricultura familiar) é associada, entre outros elementos, a relações de comunicação interpessoal ou de proximidade.

Assim, o velho debate sobre a caracterização do camponês, pode ser resumido à permanência de sociedades camponesas. Estabelecendo uma comparação, a viabilidade das unidades familiares do Nordeste semi-árido depende também das relações sócio-econômicas de redistribuição de mão de obra e de reciprocidade entre as famílias através da ajuda mútua ou mutirão, ou do compadrio. Pode-se citar o exemplo da redistribuição das terras, como as pastagens comuns no Nordeste da Bahia (os fundos de pasto) e as fontes de água comunitárias (Garcez, 1987; Vieira e Weber, 1997).

\subsection{Ambiente institucional e inovação tecnológica}

É hoje reconhecido que a construção de uma agricultura sustentável depende da produção e da validação localizada de referências diversificadas (Sebillote, 1996; Mazoyer e Roudart, 1997). Porém, para muitas situações de agricultura familiar, segundo Hocde (1997a), a prateleira de técnicas ou de referências da pesquisa agropecuária está vazia. Isto deve-se em parte às conseqüências da globalização das referências, da redução dos preços agrícolas e das novas repartições dos investimentos agropecuários. As novas exigências de mercado dos países avançados para produtos agro-alimentares de alta qualidade biológica e sanitária levaram a mudar de paradigma. A busca da qualidade vem substituir a procura da mais alta produtividade. Uma conseqüência perversa é a concentração dos financiamentos em matéria de pesquisa no setor das biotecnologias, consideradas a priori, como "limpas" (variedades transgênicas entre outras), mesmo se sofisticadas e caras. Isto é de se esperar por parte das firmas agro-industriais produtoras de insumos (sementes, adubos, agrotóxicos); infelizmente, é também o caso da pesquisa agropecuária pública.

Esta situação associada à crise da Extensão Rural pública leva ao abandono de diversos sistemas de produção, ocupando vastas áreas agrícolas no mundo. É, por exemplo, o caso da agricultura de sequeiro no semiárido nordestino que padece hoje de referências e pesquisas em diversos setores, entre outros, a produção de 
grãos e a reconstituição da fertilidade. No Agreste da Paraíba, por exemplo, os únicos atores que não param de pesquisar, experimentar e difundir inovações, são os agricultores, com meios irrisórios. Um ambiente institucional favorável e decisivo para garantir a sustentabilidade de sistemas agropecuários diversificados em zonas densamente povoadas passa pelo apoio às iniciativas inovadoras ou intensificadoras dos produtores.

Trata-se, por exemplo, da adaptação de sistemas de produção mais facilmente reprodutíveis, essencialmente a partir do baixo uso de insumos externos. A proposta é conhecida em inglês pela sigla LEISA (Low External Input and Sustainable Agriculture) e foi difundida no Brasil, entre outras, pela ONG ASPTA (Assessoria e Serviços a Projetos de Agricultura Alternativa) ${ }^{3}$ (Reijntjes et al., 1992). A lógica do sistema LEISA propõe reduzir os custos, produzindo certos insumos localmente, até na própria unidade familiar, ou valorizando melhor os recursos locais. Por suposto, esta alternativa, também tem seu preço, em particular em mão-de-obra. Por isto convêm verificar a relação final custos e rendas. As mutações tecnológicas supõem, às vezes, um esforço de validação, de transferência de tecnologia e de aprendizagem, considerável. Numa região como o Nordeste, dado o ambiente institu- cional e tecnológico, o acesso ao insumo "informação" torna-se essencial, mas, não está resolvida a questão do seu financiamento.

\section{Sustentabilidade da agricultura: questões prioritárias no Brasil}

\subsection{A reprodutibilidade agroecológica da agricultura}

A preservação dos recursos naturais (vegetação, solo, água...) e a reposição da fertilidade dos espaços cultivados constituem, normalmente, prioridades técnicas e agronômicas para qualquer agricultor familiar. Isto é, precisamente, porque sua família e o futuro dela dependem destes recursos e de como são manejados hoje. Esta perspectiva, que já tem contribuído para garantir a gestão de vastas áreas cultivadas do planeta, é nitidamente diferente da lógica de exploração imediata da floresta ou das pastagens que, geralmente, caraterizou a agricultura empresarial nas frentes pioneiras e zonas de colonização (Kitamura, 1994; Homa, 1998).

Ora, na situação de dependência e de falta de terras em que foi mantida grande parte dos pequenos produtores familiares do país, não é de se surpreender que tais práticas não sejam mais garantidas. Muitas vezes, tais medidas preservacionistas foram asseguradas pelas gerações anteriores, mas em contextos mais favoráveis quanto ao acesso à terra ou a densidade demográfica. Portanto, se for o papel de cada agricultor refletir e agir neste sentido, é também o dever dos serviços de pesquisa e extensão provocar esta reflexão e subsidiá-la com medidas concretas para garantir a reprodução da fertilidade e dos ecossistemas cultivados.

Por outra parte, grande proprietário não é sinônimo de depredação e de falta de visão em longo prazo. A própria racionalidade dos interesses econômicos privados e coletivos leva, logicamente, a preservar também a reprodução dos vastos espaços cultivados pela agricultura patronal. Hoje, no Brasil, as empresas produtoras de arroz, algodão e soja dos Cerrados no Mato Grosso e Goiás, estão cada vez mais preocupadas em gerar e validar sistemas de cultivos adaptados para permitir perenizar seus empreendimentos. As superfícies cultivadas segundo as curvas de nível, em plantio direto com adubação verde e safrinhas ${ }^{4}$, crescem a cada dia (Seguy et al., 1996). Certas práticas de adubação verde, consórcio, culturas intercaladas ou safrinha podem ser adaptadas para os sistemas de agricultura familiar mecanizados. Trabalhos como os do Instituto Agronômico IAPAR ou da AS-PTA, no Paraná, permitiram adaptar o plantio direto à pequena produção familiar com tração animal (Darolt \& Ribeiro, 1995; Hocde, 1997b).

- ${ }^{3}$ A As-pta sediada em Rio de Janeiro executa projetos nos Estados da Paraíba, Paraná, Pernambuco - e Rio de Janeiro.

- ${ }^{4}$ Cultivo "secundário" de gramíneas ou leguminosas associado a um cultivo principal, em fim de

- ciclo, destinado a proteger o solo, a ser pastado e/ou incoprorado ao solo como adubo verde. 
A principal diferença entre a agricultura familiar e a empresarial em termos de manejo de ecossistemas é o tamanho da propriedade e da parcela. Quem é proprietário ou gerente de 5.000 ou 10.000 ha de soja ou trigo subsidiados, tem a possibilidade física e financeira de manejar o conjunto de uma bacia hidrográfica, de um vale, de um maciço de relevo, ou até de uma pequena região, como bem entende. Até pode mobilizar para isto recursos públicos: pesquisa, extensão, quando não financiamentos. Para estabelecer uma comparação, a maioria dos pequenos produtores familiares do Agreste da Paraíba cultiva 2 ou 3 hectares de milho, feijão, fava e mandioca, em situação de minifúndio crescente, sem acesso à extensão e ao crédito. Geralmente continuam arando e plantando no sentido do declive (ver box 2). Continuam, mesmo quando seu vizinho já deixou de fazer assim e passou a trabalhar as encostas perpendicularmente ao declive. De fato, nem sempre se tem uma diferenciação visível ou palpável, a não ser ao longo de vários anos ${ }^{5}$, mas o problema é real e a perda de fertilidade crescente.

Uma primeira condição é, portanto, o acesso à informação. Parece evidente; mas esta informação não está disponível para o agricultor familiar, nem na cooperativa do município, nem na loja de insumos e nem sempre no escritório da exten-

Box 2:

Sustentabilidade da agricultura do Agreste da Paraíba e manejo da fertilidade

Tradicionalmente, 0 cultivo de antigas florestas subtropicais em zonas semi-áridas passa pelo respeito do pousio e por um desmatamento controlado e limitado. No Agreste da Paraíba, a pressão muito intensa sobre os recursos naturais levou ao desmatamento completo da vegetação nativa, ao abandono do pousio outrora necessário a reconstituição da fertilidade e à sucessão de cultivos nas mesmas parcelas ano após ano. Nessas condições, existem duas principais alternativas de manejo da fertilidade:

1. A associação agricultura-pecuária, procurando a reposição de fertilidade pela intensificação da criação;

2. A intensificação da produção de biomassa em todos os ambientes da propriedade inclusive pela plantação de árvores forrageiras (leguminosas) de enraizamento profundo, contribuindo para a alimentação animal e para a recomposição da fertilidade sem competir com os cultivos; A principal dificuldade no Agreste paraibana provém de circunstâncias agravantes que limitam 0 desenvolvimento de tais alternativas de manejo de fertilidade.

1. 0 desaparecimento de cultivos mercantis (fumo, sisal, algodão) provocou uma redução de renda e uma maior exploração da pecuária e dos espaços cultivados com feijão, milho e mandioca;

2. A densidade da população cresceu, levando a maioria dos produtores familiares a uma situação de minifúndio (Garcia Jr, 1990);

3. Certas práticas, como o plantio no sentido do declive, têm contribuído para a degradação do meio, sob o efeito da erosão hídrica. As parcelas não cultivadas sendo utilizadas como pastos para o gado, o superpastoreio associado a um longo período seco deixa o solo bastante exposto no inicio da estação chuvosa, aumentando os riscos de erosão quando o declive é forte;

4. A sucessão de estiagens e a seca secular de 1998, no Agreste, têm agravado o quadro. Nessas condições uma intervenção integrada e adaptada deve buscar:

- tornar mais eficientes os processos de reciclagem da matéria orgânica e dos nutrientes; - estimular a diversidade intra e inter espécies, para favorecer a estabilidade dos sistemas;

- fornecer um retorno econômico (direto ou indireto) para o agricultor e a sua família.

De fato, a intensificação dos cultivos como da pecuária não é sempre sinônimo de degradação. Aparecem práticas de reposição da fertilidade: uso dos resíduos de agave, aplicação de esterco em certos roçados e compra de esterco para o cultivo de batatinha. Por outra parte, ações de recuperação de áreas degradadas têm sucesso quando associadas a propostas de manejo da fertilidade garantindo uma maior viabilidade "individual" das unidades de produção e uma maior sustentabilidade "coletiva" dos espaços cultivados e dos seus recursos naturais: vale, baixio, encosta, micro-bacia, matas ou pastagens comunitárias, etc.

0 desafio é adaptar à diversidade dos ambientes agro-ecológicos e dos sistemas de produção, propostas alternativas de manejo e recuperação de fertilidade que não sejam somente associadas a um aumento de trabalho. Trata-se de privilegiar técnicas que permitam a utilização forrageira da biomassa ou, então, respostas rápidas em termos de ganho de fertilidade e de produtividade dos cultivos.

são rural ou do Sindicato de Trabalhadores Rurais. Muitas vezes, essa informação faz parte do referencial do extensionista local, mas, não está desenhada de maneira a ser transmitida para um público não escolarizado ou mal alfabetizado. Geralmente o técnico da extensão apenas

$\ldots \ldots \ldots \ldots \ldots$

- ${ }^{5}$ A alternativa do cultivo perpendicular ao declive não é evidente por vários motivos, a começar com - a penibilidade do trabalho, se for manual. Existe, por exemplo, a tradição de sistemas de plantio - em covas que limita a erosão. Também, segundo os agricultores, apesar de proteger a erosão do - solo, o trabalho perpendicular ao declive dificulta o trabalho de capina manual e em caso de decli-

- ve acentuado cria problemas de manejo de água: manejo das águas escoadas e repartição da água

- na parcela. 
consegue acompanhar os produtores que solicitam crédito bancário. Assim, sistemas de produção pouco exigentes em insumos físicos externos são efetivamente mais adaptados, mas na condição que exista também o "insumo informação". Esta informação pode ser local ou externa, mas tem que ser apropriada. Isto obviamente tem um custo, especificamente quando não existe organização dos produtores (Sabourin, 1998).

Assim, para abordar o tema da conservação do solo, os agricultores familiares têm que ser informados, conscientizados ou organizados. Mas isto ainda está longe de garantir uma reflexão, uma aprendizagem coletiva e, sobretudo, meios e recursos para atuar numa escala adequada: o vale, a micro-bacia, a pequena região. No Agreste paraibano, o impacto da extensão rural pública via a Emater-PB (Empresa de Assistência Técnica e Extensão Rural) é, praticamente limitado aos produtores de batatinha, os únicos da região que podem ter acesso ao crédito, e portanto à assistência técnica. $\mathrm{O}$ trabalho original de uma ONG como a AS-PTA, associada aos Sindicatos Municipais de Trabalhadores Rurais (STR), atinge também, prioritariamente, os produtores dirigentes ou membros de organizações. O passo atual do projeto da ASPTA é precisamente a organização de agricultores "experimentadores" através de grupos de interesse temáticos (batatinha, alimentação do gado, bananeira, manejo de fertilidade, etc) e geográficos (Agreste da batatinha, Brejo da banana, Curimatau de Solânea) (box 3 e As-pta, 1997).

Box 3:

Apoio à Agricultura Familiar sustentável no Agreste da Paraíba (Aspta, 1997)

0 projeto de apoio a agricultura familiar no Agreste da Paraíba conduzido pela AS-PTA em parceria com organizações de pequenos produtores dos municípios de Lagoa Seca, Remígio e Solânea (Paraíba) enfrenta os desafios especificados no box 2. 0 objetivo do projeto é dotar as organizações de produtores, em particular os STR dos três municípios, de uma verdadeira capacidade de manejo de inovação local a favor dos sistemas de produção da agricultura familiar.

0 recado da proposta é claro:

1. Uma visão agro-ecológica da agricultura de amanhã, mas sem "exigências" puristas;

2. Uma parceria privilegiada com as organizações locais sem exclusão de outras colaborações. A proposta é desenvolvida a partir de uma abordagem participativa e sistêmica. 0 enfoque de Pesquisa Ação (ou Pesquisa e Desenvolvimento) utiliza a sucessão metodológica hoje clássica:

"diagnóstico-experimentação-difusão", mas não de uma maneira linear e estrita. 0 diagnóstico é refinado pela ação de experimentação ou de desenvolvimento. A própria sistematização e avaliação em caminho das ações temáticas (monitoramento) é produtora de conhecimentos e fator de atualização do diagnóstico.

Diversos instrumentos organizativos originais e complementares dos Sindicatos de Trabalhadores Rurais e das associações comunitárias vêm sendo criados e testados na escala local: os bancos de sementes (inhame, feijão), os grupos de interesse temáticos (batatinha, alimentação animal, banana, fertilidade, inhame, amendoim, agro-floresta...) e os grupos de "Agricultoresexperimentadores" (ver box 5). 0 papel dessas formas de organização localizadas e especializadas é precisamente apoiar e sistematizar a atividade dos agricultores quanto à produção, geração, experimentação e difusão de inovações e de referências locais.
Uma intervenção integrada e eficiente, necessita da aprendizagem individual dos produtores na escala da sua parcela ou da sua roça, como também da mobilização dos grupos via as suas organizações, de maneira a garantir também uma aprendizagem coletiva. No mínimo, além da informação, da organização e da intervenção pública, uma quarta condição é necessária: a negociação. Trata-se precisamente da sensibilização, do diálogo e do planejamento necessários para poder programar e executar uma operação de conservação do solo ou do espaço cultivado (Hocde, 1997a).

\subsection{Desenvolvimento sustentável: globalização e organização local}

Cada vez mais integradas à economia internacional, as agriculturas familiares são confrontadas a fortes mutações nos planos técnico, organizacional, econômico e político. Essas transformações foram iniciadas e desenvolvidas a nível internacional, mas elas traduzem-se também ao nível nacional e local. Manifestam-se primeiro pelo desengajamento dos Estados de numerosas funções de apoio que quase sistematicamente levam para o fim das políticas de regulação de preços de subsídios (insumos, crédito e extensão) e por um amplo movimento de privatizações. Essas mudanças radicais do ambiente institucional constituem novas limitações para os produtores familiares. Mas são também novas oportunidades, libertando-os de anos de tutela.

Não é inútil lembrar que as primeiras gerações de cooperativas e associações de pequenos produto- 
res mostraram poucos resultados, porque elas foram, antes de tudo criadas e mantidas sob a tutela dos serviços do Estado, seja as EMATER, o INCRA, o DNOCS ou a CODEVASF. Cunha (1997) e Lazzaretti (1999) mostram como as atas de reunião das associações dos assentamentos de reforma agrária “modelos” da Paraíba, o Gandu, ou o Massangana III, eram utilizadas para legitimar as decisões tomadas, em realidade, pelos técnicos do INCRA. O desengajamento do estado e o poder concentrado dos macroatores privados internacionais (compras e fusões entre firmas) fortalecem a assimetria no acesso à informação e no poder de negociação, reduzindo a capacidade de competição das agriculturas locais.

Essas mudanças trazem também oportunidades. A ampliação dos mercados internos, a evolução da demanda e sua diversificação em termos de qualidade provocam uma segmentação progressiva dos mercados. Esta oferece a possibilidade de valorizar melhor as características próprias (recursos específicos) a cada situação local. O desengajamento do Estado acompanha-se de uma descentralização das tomadas de decisão ou de uma democratização da vida pública. Este contexto em evolução permanente oferece novas possibilidades de organização inovadora e autônoma, ao nível setorial e local.

Para as agriculturas familiares, isto constitui um desafio em termos de adaptação, fundamental para a sua permanência. Em numerosas situações, existe um risco forte de marginalização e de exclusão, levando à pauperização, ao êxodo rural e à degradação dos recursos naturais. Neste contexto, ninguém contesta que as propostas de desenvolvimento sustentável sejam generosas e justas ou que seus princípios devam ser divulgados e experimentados. Porém, a aplicação local destas propostas em qualquer contexto deve ser examinada com um olhar crítico.

No Brasil fala-se muito de planejamento de desenvolvimento local sustentável ou de agricultura sustentável, como se fosse uma alternativa, uma receita, que bastaria colocar em aplicação na escala local, em nível dos produtores, para melhorar a situação ou ainda para ser reconhecido pelos tomadores de decisão e pelos organismos financiadores. Em outras palavras, sustentabilidade e inserção em mercados globalizados, seriam a última oportunidade para os pequenos agricultores pegarem o "bonde do progresso e da modernização”. Ora, uma agricultura sustentável não é sinônimo de nova tecnologia como a irrigação localizada, nem de uma proposta de vida ou de mercado "alternativos" como a agricultura orgânica. Também seria redutor e ilusório assimilar a sustentabilidade dos sistemas de produção à agricultura agro-ecológica. Trata-se mais, por uma parte, de um ideal, como a justiça social,

Box 4:

O Conselho de Desenvolvimento Rural Municipal de Mirandiba-PE

Mirandiba é um município do sertão de Pernambuco, marcado pela recessão após a crise do algodã $0^{6}$. Conta hoje 10.500 habitantes (3.000 no centro urbano) repartidos em 120 comunidades ou aldeias para uma área de $800 \mathrm{~km} 2$. 0 Conselho Municipal de Desenvolvimento Rural (CMDR) criado em 1996 reúne os representantes da Prefeitura Municipal, dos órgãos técnicos estaduais, da sociedade civil (igreja, sindicatos, ong's,..) e representantes dos produtores. A sua originalidade foi optar por um sistema de representação das comunidades rurais através da eleição de 20 representantes correspondendo a 20 pólos associativos do município, já que é impossível contar com um membro de cada associação local. A maioria dos CMDR da região resolveu o problema convidando unicamente a um representante do Sindicato de Trabalhadores Rurais, do Sindicato da Agricultura Patronal e de alguma organização de produtores patrocinada pela prefeitura

Assim os agricultores familiares conseguem dispor da maioria entre os 37 membros do Conselho. Este detalhe mudou completamente a natureza dos projetos realizados por meio de fundos públicos, como o Pronaf ou os subsídios do Estado de Pernambuco e do Banco Mundial (programa Prorural). Para o manejo da água na zona rural por exemplo, quando a Prefeitura e 0 Estado tinham projetado três grandes projetos centralizados de bombeamento e armazenamento de água com energia solar ou eólica (US\$ 30.000 cada), os representantes dos agricultores no Conselho têm exigido não menos que dez pequenos projetos menos vistosos, de menor custo e assegurando uma melhor repartição decentralizada do manejo da água, além de soluções técnicas socialmente e tecnicamente apropriáveis e manejáveis pela população local.

- ${ }^{6}$ Além da queda dos preços, a partir de 1985, o algodão desapareceu da região por causa do ataque do bicudo (Anthonum grandis). A AS-PTA intervêm no município de Mirandiba a pedido da prefeitura para contribuir, experimentar e difundir alternativas de armazenamento e manejo de água na zona rural. 
e por outra parte, de um projeto de sociedade que deve ser construído tecnicamente, socialmente e politicamente.

Seria assim um mito perigoso passar a idéia de que apenas os agricultores e os trabalhadores sem terra de uma região marginalizada como o Nordeste semi-árido têm um papel essencial e uma responsabilidade perante as gerações futuras em matéria de desenvolvimento sustentável. Eles têm a mesma responsabilidade que qualquer cidadão em não depredar o meio ambiente e os recursos naturais locais. Mas têm, antes de tudo, a responsabilidade e o dever de alimentar as suas famílias e de lutar pelos seus direitos como o acesso à terra, ao emprego, à moradia e à cidadania.

Até hoje, o principal mérito das propostas de desenvolvimento sustentável nos Estados do Nordeste (Magalhães, 1995) e do Programa de Fortalecimento da Agricultura Familiar do Governo Federal (Pronaf) foi de ter acelerado a criação de espaços e estruturas locais de negociação dos recursos públicos para a agricultura familiar. São os chamados "Conselhos Municipais de Desenvolvimento Rural” (ver box 4). Estes podem constituir os primeiros passos de uma política diferenciada de desenvolvimento territorial para a agricultura familiar (Abramovay, 1998). Apesar das dificuldades enfrentadas no Nordeste, qualquer negociação dos projetos e orçamentos locais, mesmo no marco de um conselho municipal assimétrico, manipulado e sem verdadeiro poder de decisão e de execução, já cria um precedente, depois do qual será sempre difícil voltar atrás.

\subsection{Gestão da inovação: grupos de interesse e agricultores- experimentadores}

Contudo, existem funções que são dificilmente assumidas pelos Conselhos Municipais e pelas organizações de produtores familiares, por falta de experiência, de meios ou de estruturas de apoio adequadas. É, por exemplo, o caso da geração, adaptação e difusão técnica, onde a articulação entre ação pública (os serviços do Estado) e ação individual (o agricultor) passa por diversos problemas, entre outros de comunicação (Hocde, 1997a). No entanto aparecem, pouco a pouco, novas estruturas de produtores especializadas em matéria de gestão local da inovação. São, em primeiro lugar, os "grupos de interesse temático" que surgiram nos Municípios de Juazeiro e Pintadas na Bahia, ao exemplo do Projeto Massaroca, apoiado pela Embrapa Semi-Árido ou as “comis- sões temáticas" no Perímetro Irrigado Nilo Coelho, em Petrolina-PE. Mais recentemente, no Agreste da Paraíba, foram criadas estruturas novas, ligadas às associações comunitárias (bancos de sementes e fundos rotativos para a construção de cisternas em Solânea), aos STR (banco de esterco em Lagoa Seca) ou a redes sócio-técnicas (grupos de agricultores-experimentadores em Remígio e Solânea) ( ver box 5 e Sidersky e Silvera, 1998; Sabourin, 1998).

Essas experiências constituem uma das vias de geração e difusão de referências adaptadas a uma agricultura familiar sustentável. São alternativas possíveis, quando as interações são suficientemente densas entre o nível da unidade de produção (ação individual) e o da ação pública, por meio de diversos agentes ou mediadores situados em níveis intermediários: por exemplo, as organizações de produtores como o

Box 5:

Os grupos de Agricultores-Experimentadores (A-E) do Agreste da Paraíba

Os grupos de A-E são constituídos por agricultores inovadores que experimentam empiricamente técnicas, práticas ou processos na sua propriedade de maneira espontânea, por incentivo mútuo ou por incentivo institucional. Esses grupos reúnem produtores de uma mesma localidade ou envolvidos numa mesma problemática de produção agropecuária, determinada por fatores agro-ecológicos, sociais, geográficos ou técnicos, como, por exemplo, o grupo do Curimataú do Município de Solânea ou aquele da região do Gravatá do Município de Remígio. No Nordeste, os primeiros grupos estruturados foram criados com apoio dos STR de Remígio e Solânea (PB) e são acompanhados ao nível técnico e metodológico pela AS-PTA. Os grupos mantém uma ligação forte com os STR dos três município, e segundo os locais, com as associações comunitárias.

A definição global do tipo de experimento é realizada de maneira coletiva por meio de reuniões de programação por localidade. 0 acompanhamento dos experimentos é realizado conjuntamente pelos produtores, pelos técnicos e alguns monitores (agricultores membros da equipe permanente do STR municipal). Existe um monitoramento individual temático (cada experimento de cada agricultor) e um monitoramento integrado e coletivo por meio de eventos de intercâmbio ou de socialização da informação (visitas ou reuniões de programação e avaliação). A socialização final dos resultados e das referências é realizada mediante uma reunião de avaliação no fim do ciclo agrícola ou do ano. Pode ser também na ocasião de um encontro técnico, de um seminário de capacitação ou ainda de uma festa local ou regional, organizada pelo STR e pelos A-E 
Comitê de Associações Agropastoris de Massaroca ou os STR de Remígio e Solânea na Paraíba, as ONG, como a ASPTA ou a ADAC em Juazeiro. São instituições que operam ao nível da ação coletiva. Estes diversos níveis de organização da inovação localizada não são definidos a priori, de maneira administrativa, como o município. Mantêm, porém, uma coerência geográfica (bacia de drenagem, baixio, vale), técnica (perímetro irrigado) ou social (comunidade, assentamento de reforma agrária). Trata-se de um nível onde existe uma coesão entre agricultores, produto do cruzamento entre solidariedades territoriais (espaços de proximidade, localidade, bacia de produção) e organizações profissionais ou econômicas, geralmente determinadas pelas cadeias produtivas e pelas interfaces com o mercado.

\section{Conclusão}

A proposta de uma agricultura ecologicamente e socialmente sustentável constituí uma verdadeira utopia. Segundo Dover e Talbot (1992) que falam de "sonho", ela tem que respeitar o meio ambiente e o homem (as mulheres, os jovens, os pobres); ela deve integrar os marginalizados, e finalmente, gerar emprego e renda no meio rural. São desafios que começam com a manutenção do potencial de fertilidade dos ecossistemas cultivados ou pastados, mas que nunca acabam. Por outro lado, se os agricultores familiares e as entidades que os apoiam, não aproveitam este discurso globalizado, essa dinâmica unânime, para lutar por este sonho, ninguém o fará no lugar deles. $\mathrm{O}$ respeito de tais parâmetros depende de enfrentamentos. Portanto, os agricultores familiares estão obrigados, "condenados” até, a se organizar para negociar, para planejar o seu futuro e para lutar contra a exclusão.

Entre o nível da ação individual (o agricultor) e aquele da ação pública (políticas públicas, crédito, infra-estruturas, educação...), o ambiente institucional inclui hoje o nível da ação coletiva ou, com outras palavras, aquele da organização dos atores do desenvolvimento local, incluindo os produtores familiares. Este nível é fundamental para articular negociações entre indivíduos e poderes públicos, para constituir redes e alianças capazes de mobilizar e de provocar uma resposta da ação pública, entre outras, para a produção e difusão de inovações adaptadas.

A organização autônoma dos produtores constitui, sem dúvida, uma primeira condição de sustentabilidade social e econômica da agricultura familiar. Mais que uma resistência, esta organização passa por uma série de adaptações permanentes: atualização das formas de solidariedade familiar e de reciprocidade camponesa à um novo contexto institucional; adaptação do "saber-fazer" camponês em matéria de produção e processamento a novas exigências do mercado. Esta adaptação traduz-se em termos de inovação institucional, técnica e econômica. Pode ser ilustrada através da diversidade das formas institucionais referenciadas na segunda parte, a exemplo dos Sindicatos de Trabalhadores Rurais da Paraíba, do Conselho de Desenvolvimento Rural
Municipal de Mirandiba (PE), dos grupos de interesse Massaroca (BA) ou de "agricultores experimentadores” do Agreste paraibano.

\section{Bibliografia}

ABRAMOVAY, R. Paradigmas do capitalismo agrário em questão. São Paulo: HUCITEC/ANPOCS/ UNICAMP, 1992, 275p.

ABRAMOVAY, R.; VEIGA, J. E. Análise da inserção do PRONAF na política agrícola, Brasília: Convênio FIPE/IPEA, relatório final, 1998, $74 p$.

ABRAMOVAY, R. Bases para a formulação da política brasileira de desenvolvimento rural: Agricultura familiar e desenvolvimento territorial. Brasília: Convênio FIPE/IPEA, relatório final, 1998, 15p

AS-PTA. Trajetória do projeto Paraíba: 1993-1996, Recife: ASPTA, 1997, 33p.

BANCO MUNDIAL. World Development Report: Poverty. Washington, USA, World Bank, 1990.

BANCO MUNDIAL. Brasil: o gerenciamento da agricultura, do desenvolvimento rural e dos recursos naturais. S. 1.,. Brasília: Banco Mundial, (Relatório n ${ }^{\circ}$ 11738-BR), 1993

BILLEAUD, J. P. Lagriculture durable dans les pays développés: un concept peu controversé mais bien incertain. in: Workshop "Desenvolvimento de uma outra agricultura..." Anais, Vol I, Curitiba: UFPR, outubro de 1995. 
CARVALHO, T. A. de A. Agricultura Sustentável na unidade familiar de produção: um novo paradigma de desenvolvimento: in Workshop "Desenvolvimento de uma outra agricultura...", Anais, Vol II, Curitiba: UFPR, outubro de 1995.

CHAYANOV, A. V. The Theory of Peasant Economy, Illinois, USA: American Economic Association, 1966.

CHAMBERS, R; CONWAY, G. R. Sustainable rural livelihoods. Practical concepts for the 21th century. Brighton, Inglaterra: IDS, (IDS Discussion Paper, 296), 1992.

CMMAD, Comissão Mundial para o Meio Ambiente e o Desenvolvimento. Nosso futuro comum, Rio de Janeiro: FVG, 1991, 430p., 2da edição.

CUNHA, L. H. H. Vulnerabilidade a seca e Sustentabilidade nos Assentamentos d Reforma Agrária no semi-árido nordestino. Campina Grande-PB: UFPB-CH, 1997, 135p. Dissertação de Mestrado em Sociologia.

DAROLT, M. R.; RIBEIRO, M.de F. Pesquisa-desenvolvimento sustentável: experiência com plantio direito para pequena propriedade. In: Encontro da Sociedade Brasileira de Sistemas de Produção, 2. Anais: 1995, Londrina, 291-301.

DELGADO, G. C. Agricultura familiar e política agrícola no Brasil. In: Ramos \& Reydon (Org.) Agricultura e agroindústria no Brasil, Campinas: ABRA, 1995, 199-235.
DOVER, M. J; TALBOT, L. M. Paradigmas e princípios ecológicos para a agricultura. Rio de Janeiro: AS-PTA, Textos para Debate $\mathrm{N}^{\circ} 44$, 1992, 42p.

EHLERS, E. Agricultura sustentável: origens e perspectivas de um novo paradigma. São Paulo: Livros da Terra, 1996.

ENGEL, P. G. H. The social organization of innovation. A focus on stakeholder interaction. Amsterdam, Holanda: Royal Tropical Institute, CTA, 1998, 238p.

GARCEZ, A. N. Fundos de Pasto: um projeto de vida sertanejo. Salvador: InterBa-CAR,1987, 107 p.

GARCIA Jr, A. R. O sul: caminho do roçado. São Paulo: Marco Zero, Brasilia: Unb, MCT, CNPq, 1989, 285p.

HOCDE. H. "No quiero plata, Quiero conocimientos" No equivocarse de planteamiento !. San José, Costa Rica: IICA-PRIAG, série estratégica, 22, 1997a, 55 pp.

HOCDE, H. "Sueño: pesadilla o utopia” Relatório de una visita del trabajo de As-pta en la región Centro-Sur del estado de Paraná, Brasil. San José, Costa Rica: DER, PRIAG, 1997b, 22p.

HOMA, A. O. As questões emergentes e a Agricultura da Amazônia. Palestra no Workshop "Agricultura e desenvolvimento sustentável na Amazônia”, Belém-PA: Embrapa Amazônia Oriental, 28-30 de abril de 1998.
KITAMURA, P. C. A Amazônia e o Desenvolvimento Sustentável, Brasília: Embrapa, 1994, 182p.

LAMARCHE, H. (Coord.) A agricultura familiar (I) Comparação internacional. Campinas: Edi Unicamp, 1993, 348p;

LANDAIS, E. Agriculture durable et nouveau contrat social. Courrier de l'Environnement de l'INRA, $n^{\circ}$ 38, abril de1998, 18p.

LAZZARETTI, M. A; SABOURIN, E. Ação coletiva e organização de produtores: o caso do Assentamento, Massangana III. In: III Semana de Pesquisa, Ensino e Extensão do Centro de Humanidades, Campina Grande-PB: UFPB-CH, 8-12 de novembro 1999, 8p.

LEROY, JP, Entrevista in Proposta $n^{\circ}$ 77, pp 33-41, junho de 1998.

MAGALHÃES. A. R. Um estudo de desenvolvimento sustentável do Nordeste semi-árido. In: Desenvolvimento e natureza: um estudo para uma sociedade sustentável. Cavalcanti C. (Org.) São Paulo: Cortez ; Recife: Fundaj,1995.

MAZOYER, M.; ROUDART, L. Histoire des agricultures du monde. Paris, França. Le Seuil, 1997, 534p.

MENDRAS, H. Sociedades Camponesas, Rio de Janeiro, Zahar, 1978.

OLIVEIRA, C. A. de V; COELHO, R.; BONNAL, P. CAVALCANTI, $\mathrm{N}$ de B. Tipologia dos Sistemas de Produção praticados pelos pequenos 
produtores do Estado do Ceará. In: XXXV Congresso Brasileiro de Economia e Sociologia Rural, Natal, agosto 1997, Anais: Brasília, SOBER, 1997, pp 260-262.

REINJTJES, C.; HAVERKORT, B.; WATERS-BAYER, A. Farming for the Future: an introduction to Low External Input and Sustainable Agriculture. London \& Basingstoke, England: The Macmillan Press Ltd, 1992, 354p.

SABOURIN, E. Organização dos produtores familiares para a produção e difusão da inovação no Agreste da Paraíba, Relatório de Atividade. Campina Grande-PB: UFPB-CH, CNPq, 1998, 80p.

SABOURIN, E. 1999 Organização dos produtores e ação coletiva: reflexão a partir de estudo de casos no Nordeste brasileiro. In: Organização dos produtores, Sperry S. (coord.) Brasília, Embrapa-CTT, série "Agricultura Familiar, 3", pp 103-127.

SEBILLOTTE, M. RecherchesSystème et action. In: Symposium International sur les Recherches Système en Agriculture et Développement rural, 1994: Conférences et débats, Montpellier, CIRAD-SAR, 1996, pp 39-79, ,

SEGUY,L; BOUZINAC, S.; TRENTINI, A.; CORTES, N. A. A agricultura brasileira das frentes pioneiras In: Agriculture et Développement, $n^{\circ} 12$, pp 2-60, dezembro de 1996

SIDERSKY, P.; SILVERA, L.M. Experimentar com os agricultores. A experiência da AS-PTA na Para- íba, Recife: AS-PTA, 1998, 15p. mimeo

STIGLITZ, J., "More Instruments and Broader Goals: Moving toward the Post Washington Consensus", in Wider Annual lectures 2; Tokyo, Japão: UNU World Institute for Development Economics Research, 1998a, 39p

STIGLITZ, J., "Distribution, Efficiency and Voice: Designing the Second Generation of Reforms" Conference on Asset Distribution, Poverty and Economic Growth Brasília: Ministério Extraordinário de Políticas Fundiárias e Banco Mundial, Julho de 1998, 20p

VEIGA, J. E. da. Problemas da transição à agricultura sustentável. In: Estudos Econômicos, Número especial do ano 1994, pp 9-29.

VEIGA. J. E. da Mudanças na relação cidade-campo. In: Estado de São Paulo, 29-08-1998

VIEIRA, P. F.; WEBER, J. (Org.) Gestão de recursos naturais renováveis e desenvolvimento" São Paulo: Cortez Editora, 1997, 430p.

VIEIRA O. J. A de. Reconversão dos pequenos agricultores de tipo familiar: uma exigência de cidadania. In: Workshop "Desenvolvimento de uma outra agricultura...”, Anais, $\mathrm{Vol}$ I, Curitiba: UFPR, outubro de 1995. 